\title{
Author Correction: Nanoscale-femtosecond dielectric response of Mott insulators captured by two-color near-field ultrafast electron microscopy
}

\author{
Xuewen Fu (D), Francesco Barantani D, Simone Gargiulo (D), Ivan Madan, Gabriele Berruto, Thomas LaGrange, \\ Lei Jin, Junqiao Wu (D), Giovanni Maria Vanacore (1), Fabrizio Carbone (1) \& Yimei Zhu
}

Correction to: Nature Communications https:/doi.org/10.1038/s41467-020-19636-6, published online 13 November 2020.

The original version of this Article contained errors in the captions of Figs. 2 and 4 and their corresponding main text. In the caption of Fig. 2, right panels should read right panel; middle panel should read right panel. In the caption of Fig. $4, t_{2}=0$ ps (coincidence between pump and probe, blue curve) and 1.28 ps (green curve) should read $t_{2}=-0.4$ ps (coincidence between pump and probe, blue curve) and $0.8 \mathrm{ps}$ (green curve); $t_{2}=0 \mathrm{ps}$ (blue curve) and $1.28 \mathrm{ps}$ (green curve) should read $t_{2}=-0.4$ ps (blue curve) and 0.8 ps (green curve). In the main text of page 5, VO2 NWs should read $\mathrm{VO}_{2} \mathrm{NWs}$. In the main text of page 6, the blue box in the right panel should read the blue box in the middle panel; $t_{2}=0$ ps and $t_{2}=1.28$ ps should read $t_{2}=-0.4$ ps and $t_{2}=0.8$ ps; decrease at 1.28 ps should read decrease at $0.8 \mathrm{ps}$; a time constant of $\sim 145 \mathrm{fs}$ should read a time constant of $\sim 155 \mathrm{fs}$; a time constant of $\sim 155 \mathrm{fs}$ should read a time constant of $\sim 240 \mathrm{fs}$.

This has been corrected in both the PDF and HTML versions of the Article.

Published online: 01 April 2021

Open Access This article is licensed under a Creative Commons Attribution 4.0 International License, which permits use, sharing, adaptation, distribution and reproduction in any medium or format, as long as you give appropriate credit to the original author(s) and the source, provide a link to the Creative Commons license, and indicate if changes were made. The images or other third party material in this article are included in the article's Creative Commons license, unless indicated otherwise in a credit line to the material. If material is not included in the article's Creative Commons license and your intended use is not permitted by statutory regulation or exceeds the permitted use, you will need to obtain permission directly from the copyright holder. To view a copy of this license, visit http://creativecommons.org/licenses/by/4.0/.

(C) The Author(s) 2021 